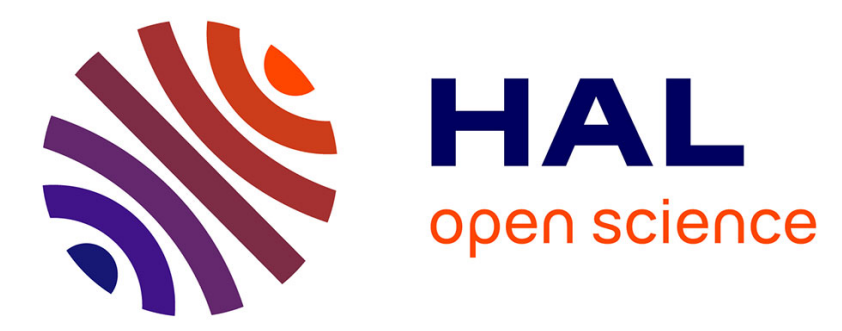

\title{
Dose-dependent response of nitrogen stable isotope ratio to proportion of legumes in diet to authenticate lamb meat produced from legume-rich diets
}

T. Devincenzi, Olivier Delfosse, Donato Andueza, C. Nabinger, Sophie Prache

\section{- To cite this version:}

T. Devincenzi, Olivier Delfosse, Donato Andueza, C. Nabinger, Sophie Prache. Dosedependent response of nitrogen stable isotope ratio to proportion of legumes in diet to authenticate lamb meat produced from legume-rich diets. Food Chemistry, 2014, 152, pp.456-461. 10.1016/j.foodchem.2013.11.164 . hal-01268557

\section{HAL Id: hal-01268557 \\ https://hal.science/hal-01268557}

Submitted on 27 May 2020

HAL is a multi-disciplinary open access archive for the deposit and dissemination of scientific research documents, whether they are published or not. The documents may come from teaching and research institutions in France or abroad, or from public or private research centers.
L'archive ouverte pluridisciplinaire HAL, est destinée au dépôt et à la diffusion de documents scientifiques de niveau recherche, publiés ou non, émanant des établissements d'enseignement et de recherche français ou étrangers, des laboratoires publics ou privés. 


\title{
Dose-dependent response of nitrogen stable isotope ratio to proportion of legumes in diet to authenticate lamb meat produced from legume-rich diets
}

\author{
T. Devincenzi ${ }^{\mathrm{a}, \mathrm{c}}$, O. Delfosse ${ }^{\mathrm{b}}$, D. Andueza ${ }^{\mathrm{a}}$, C. Nabinger ${ }^{\mathrm{c}}$, S. Prache ${ }^{\mathrm{a}, *}$ \\ a Institut National de la Recherche Agronomique (INRA), UMR1213 Herbivores, F-63122 St-Genès-Champanelle, France \\ ${ }^{\mathrm{b}}$ Institut National de la Recherche Agronomique (INRA), UMR0614 Fractionnement des Agro Ressources et Environnement, 2 esplanade Roland-Garros, \\ BP 224, F-51686 Reims Cedex 2, France \\ ${ }^{\mathrm{c}}$ Universidade Federal do Rio Grande do Sul (UFRGS), Av. Bento Gonçalves 7712, CEP 91501-970, Porto Alegre, RS, Brazil
}

\section{A R T I C L E I N F O}

\section{Article history:}

Received 5 June 2013

Received in revised form 25 October 2013

Accepted 28 November 2013

Available online 7 December 2013

\section{Keywords}

$\delta^{15} \mathrm{~N}$

Nitrogen stable isotope ratio

Lamb meat

Authentication

Legumes

\begin{abstract}
A B S T R A C T
This study investigated the dose-dependent response in lamb meat of stable nitrogen isotope ratio to the dietary proportion of legumes, and the ability of the nitrogen isotope signature of the meat to authenticate meat produced from legume-rich diets. Four groups of nine male Romane lambs grazing a cocksfoot pasture were supplemented with different levels of fresh alfalfa forage to obtain four dietary proportions of alfalfa $(0 \%, 25 \%, 50 \%$ and $75 \%$ ) for 98 days on average before slaughter (groups L0, L25, L50 and L75). We measured the stable nitrogen isotope ratio in the forages and in the longissimus thoracis muscle. The $\delta^{15} \mathrm{~N}$ value of the meat decreased linearly with the dietary proportion of alfalfa. The distribution of the $\delta^{15} \mathrm{~N}$ values of the meat discriminated all the L0 lambs from the L75 lambs, and gave a correct classification score of $85.3 \%$ comparing lambs that ate alfalfa with those that did not.
\end{abstract}

(c) 2013 Elsevier Ltd. All rights reserved.

\section{Introduction}

In recent years, there has been renewed interest in incorporating forage legumes within livestock systems in order to reduce the reliance on bought-in concentrate feed, prevent the contamination of soil and water from excessive amounts of synthetic fertilizers and meet consumer demands for a healthy product produced in a natural way. Organic farming systems are particularly concerned due to the high cost of organic concentrate feed and because the organic farming list of specifications forbids the use of synthetic fertilizers. Moreover, there is a growing consumers' interest in the environment, animal welfare and the origin and method of food production and consequently for food products of low-input and organic production systems. The ability to authenticate food products from these agro-ecological systems has therefore become an important challenge for scientists, monitoring bodies, commercial organizations and farmers alike.

The nitrogen $(\mathrm{N})$ isotope signature has recently been proposed as a valuable tool to authenticate meat produced from pasturefed animals (Monahan et al., 2012) and more specifically from organic beef (Schmidt et al., 2005; Bahar et al., 2008). Schmidt et al.

\footnotetext{
* Corresponding author. Tel.: +33473624063.

E-mail address: sophie.prache@clermont.inra.fr (S. Prache).
}

(2005) observed a lower ${ }^{15} \mathrm{~N} /{ }^{14} \mathrm{~N}$ ratio in the meat of organically raised beef compared with conventionally raised animals. They suggested that this difference might be related to differences in the composition of the diet, with more legumes in the diet of organically raised animals. The $\mathrm{N}$ stable isotope composition of animal products is directly related to the dietary ${ }^{15} \mathrm{~N} /{ }^{14} \mathrm{~N}$ ratio which is lower in legume-rich diets due to the capacity of leguminous plants to fix atmospheric nitrogen (DeNiro \& Epstein, 1981; Bahar et al., 2005). However, many of the studies using stable isotopes have limited their comparisons to the authentication of geographical locations, and no clear conclusions are drawn concerning the authentication of diet composition (Piasentier, Valusso, Camin, \& Versini, 2003; Camin et al., 2007; Vinci, Preti, Tieri, \& Vieri, 2012; Yanagi et al., 2012).

The aim of this study was to investigate the dose-dependent response in lamb meat of stable $\mathrm{N}$ isotope ratio to the proportion of legumes in the lambs' diet and the ability of the $\mathrm{N}$ isotope signature of the meat to authenticate meat produced from legume-rich diets.

\section{Materials and methods}

The experiment took place at the Herbivore Research Unit at the Institut National de la Recherche Agronomique (INRA) ClermontFerrand/Theix Research Centre, France. The animals were handled 
by specialised staff who ensured their welfare in accordance with European Union Directive No. 609/1986.

\subsection{Experimental design, animals and diets}

We compared four proportions of alfalfa (Medicago sativa) and cocksfoot grass (Dactylis glomerata L.) in the animal's diet, using four groups of lambs. Each experimental treatment comprised nine non-castrated male Romane lambs that were fed, for 98 days on average before slaughter, a diet containing 0\%:100\% (L0), 25\%:75\% (L25), 50\%:50\% (L50) and 75\%:25\% (L75) fresh alfalfa forage:fresh cocksfoot forage. The lambs received no legumes in their diet before the experiment began.

Two conterminal monocultures of alfalfa ( 1.0 ha) and cocksfoot (1.6 ha) were sown in October 2010. From 30 April 2012 onwards, both pastures were divided into four plots of similar area. Each week, one plot was mown to ensure the provision of young forage throughout the experiment. In March 2012, both pastures received $67 \mathrm{~kg}$ phosphorus/ha and $100 \mathrm{~kg}$ potassium/ha. In April 2012, the cocksfoot pasture received $48 \mathrm{~kg} \mathrm{~N} / \mathrm{ha}$.

Lambs were born between 18 March and 26 March 2012. Before the experimental period, the animals were managed uniformly and received no legumes in their diet (i.e. from the beginning of the gestation period for the dams). Between birth and 10 May, the lambs and their dams were housed in a sheepfold, and the lambs were offered a commercial concentrate. From 04 May to 10 May, the lambs were offered freshly cut cocksfoot grass, distributed indoors. Lambs and their dams were then turned out to two unmown plots of the cocksfoot pasture from 11 May to 29 May. To remove the stemmy material over the whole cocksfoot pasture and ensure a vegetative regrowth, the cocksfoot pasture was topped on 29 May with a forage harvester, and the trimmings removed.

On 30 May, the 36 lambs were assigned to nine blocks according to birth weight and average daily gain (ADG) between birth and 29 May. They were then randomly assigned from within the blocks to one of the four treatments. Mean lamb birth weight and ADG between birth and 29 May were 4.2 (standard deviation (SD): 0.71) kilogram (kg) and 301 (SD 49.6) gram per day (g/d); lambs weighed 24.9 (SD 3.49) $\mathrm{kg}$ on 29 May, i.e. at a mean age of 69 (SD 1.9) days. The lambs were weaned and treated against internal worms on 29 May, and then individually penned indoors for an adaptation period until 7 June. During this adaptation period, the lambs were fed freshly cut cocksfoot ad libitum.

Period 1. From 7 June until 3 July, the lambs were individually fed indoors. During this period, L0, L25, L50 and L75 lambs were fed a diet containing 0\%:100\%, 25\%:75\%, 50\%:50\% and 75\%:25\% alfalfa:cocksfoot freshly cut forages respectively (on a dry matter basis). The levels of alfalfa and cocksfoot offered were calculated every day (except on weekends) to ensure similar levels of Unités Fourragères Viande (UFV) for all the groups (INRA, 2007), and based on the estimation of the dry matter (DM) content of each forage offered. This last estimation was made in duplicate using a microwave oven. Both forages were cut daily at 8 ante meridiem (a.m.) and offered in separate tubs, half in the morning at 9 a.m., and half in the afternoon at 4 post meridiem (p.m.) after storage at $4{ }^{\circ} \mathrm{C}$. Feed tubs were emptied every morning before the distribution of the freshly cut forages, and refusals were weighed, recorded and discarded. Final dry matter measurement was made daily in duplicate for both forages by drying representative samples of the forages offered and refused in a forced-air oven for $72 \mathrm{~h}$ at $60{ }^{\circ} \mathrm{C}$. We initially planned to use this feeding scenario throughout the fattening period between weaning and slaughter, in order to control the proportions of cocksfoot grass and alfalfa for each lamb. However, this plan was thwarted by low levels of forage intake, which resulted in low levels of ADG. We therefore adapted the experimental design during the second part of the study (Period 2).
Period 2. From 4 July 2012 until slaughter, each group of lambs was assigned to one of the four cocksfoot pasture plots and supplemented with freshly cut alfalfa using racks. The mean voluntary intake level of each lamb group was estimated at $78.125 \mathrm{~g} \mathrm{DM} /$ $\mathrm{BW}^{0.75}$, where $\mathrm{BW}$ was the average body weight of the group (Hassoun \& Bocquier, 2007). The amount of fresh alfalfa offered to each group was based on the assigned proportion of alfalfa in the diet and the estimation of the dry matter content of fresh alfalfa. This estimation was made in duplicate using a microwave oven. Alfalfa was cut every morning at 8 a.m. and offered half in the morning at 9 a.m., and half in the afternoon at 4 p.m. after storage at $4{ }^{\circ} \mathrm{C}$. Care was taken to use sufficiently large racks to avoid competition for alfalfa. The racks were emptied every morning before the distribution of the freshly cut alfalfa and the refusals were weighed, recorded and discarded. Representative samples of offered and refused alfalfa were collected daily for final dry matter measurements made in duplicate by drying in a forced-air oven for $72 \mathrm{~h}$ at $60{ }^{\circ} \mathrm{C}$. Water and salt blocks were always available. The salt blocks contained (g/kg, as-fed) 60 Calcium, 20 Phosphorus, 10 Magnesium, 280 Sodium, 17.5 Zinc, 1.5 Iron, 5.5 Manganese, 0.03 Cobalt, 0.03 Iodine, and 0.01 Selenium.

The cocksfoot pasture was grazed continuously during Period 2, but the experimental groups of lambs were changed weekly from one cocksfoot plot to another to avoid confounding effects of sward characteristics for cocksfoot forage intake level. All lambs received anthelmintic drenches at weaning and then monthly.

\subsection{Slaughter procedures}

Groups of lambs balanced for treatments were slaughtered at the INRA Clermont-Ferrand Centre experimental slaughterhouse, according to European Union welfare guidelines, on 3 September 2012 (three lambs per group), 6 September (two lambs per group) and 27 September 2012 (four lambs per group). They were thus slaughtered at mean age 177 (SD 11.6) days after having been fed the experimental treatment for 98 days on average (range: 86-112 days). The lambs had access to food and water until approximately $30 \mathrm{~min}$ before slaughter and were transported by truck to a slaughterhouse located less than $500 \mathrm{~m}$ from the experimental pastures. Immediately on arrival, the lambs were electrically stunned and slaughtered by throat cutting.

\subsection{Measurements}

\subsubsection{Animal body weight}

Lambs were weighed once weekly before the alfalfa distribution in the morning.

\subsubsection{Pasture availability}

Fifty systematic measurements of the cocksfoot sward surface height per plot were made weekly using a sward stick.

\subsection{3. $N$ isotope ratio mass spectrometry}

$\mathrm{N}$ stable isotope ratio analysis of the forages was performed weekly on dried samples milled with a $200 \mu \mathrm{m}$ outlet mill. During Period 2, for the cocksfoot pasture, snip samples representative of the plant material consumed by the lambs, i.e. about $50 \%$ of the extended tiller height (Prache \& Peyraud, 2001), were taken weekly in each cocksfoot plot, dried for $72 \mathrm{~h}$ at $60^{\circ} \mathrm{C}$, and milled with a $200 \mu \mathrm{m}$ outlet mill. Bulked samples were then made, grouping the four plot samples.

A sample of the left longissimus thoracis (LT) muscle was taken from the last thoracic rib 24 hours (h) post mortem, vacuum packed and frozen at $-20^{\circ} \mathrm{C}$, freeze-dried, and milled in a CYCLOTEC grinder with a 0.8 millimeter $(\mathrm{mm})$ outlet grid of $200 \mu \mathrm{m}$. 
$\mathrm{N}$ stable isotope ratio analysis of meat and forage samples was carried out as follows. The sample powder was first homogenised, and an aliquot of about 4 milligram ( $\mathrm{mg}$ ) was then weighed in a tin capsule. The capsule was analysed using a EURO EA elemental analyser (Eurovector, Milan, Italy) connected to a delta PLUS advantage isotope ratio mass spectrometer (Thermo-Fischer, Bremen, Germany). The sample was fully oxidised. Nitrogen was converted into $\mathrm{N}_{2}$ and carbon into $\mathrm{CO}_{2}$. A Porapack-QS column was used to separate the two gases, which were then introduced into a mass spectrometer. After ionisation, electrical field acceleration and magnetic field deviation steps, the ions were detected using Faraday cups, and the ${ }^{15} \mathrm{~N} /{ }^{14} \mathrm{~N}$ isotope ratio was calculated. Hereafter, ${ }^{15} \mathrm{~N} /{ }^{14} \mathrm{~N}$ isotope ratio is expressed using the $\delta^{15} \mathrm{~N}$ value, calculated as follows:

$\delta^{15} \mathrm{~N}=\left(\left[\left({ }^{15} \mathrm{~N} /{ }^{14} \mathrm{~N}_{\text {sample }}\right)-\left({ }^{15} \mathrm{~N} /{ }^{14} \mathrm{~N}_{\text {air }}\right)\right] /\left({ }^{15} \mathrm{~N} /{ }^{14} \mathrm{~N}_{\text {air }}\right)\right) \times 1000$.

\subsection{Data analysis}

The data for the $\delta^{15} \mathrm{~N}$ value of the meat underwent a variance analysis using the General Linear Model (GLM) procedure of SAS software package (Inst. Inc., Cary, NC) to examine the effect of the feeding treatment. We used the Duncan test for pairwise comparisons. A regression analysis was carried out using the GLM procedure of SAS software package to examine whether the response of mean $\delta^{15} \mathrm{~N}$ of the meat had a linear or a curvilinear relation (quadratic effect) to the mean proportion of alfalfa in the diet.

Linear discriminant analysis (LDA) was performed on $\delta^{15} \mathrm{~N}$ values of the longissimus thoracis muscle to classify the meat samples according to feeding treatments, using Minitab software v.13 (Minitab Inc., Paris). Linear discriminant analysis is a pattern recognition method which characterizes two or more classes of objects. The model was tested using a cross-validation procedure in which each meat sample was temporarily removed from the initial data set to be used for validation. The LDA models were developed based on the other meat samples and used to classify the validation sample. This procedure was repeated until all data set meat samples had been used through the validation procedure. This analysis was performed to evaluate the reliability of the discrimination between pairwise groups, between lambs consuming no alfalfa (L0 lambs) and those consuming alfalfa (L25, L50 and L75), and between all four groups of lambs.

\section{Results}

\subsection{Pasture, animal performance, and intake}

During the study, one lamb in group L75 died from bloating and one lamb in group L0 died from causes unrelated to the experimental treatments.
Mean sward surface height over the whole cocksfoot pasture averaged $14.8 \mathrm{~cm}$, ranging from $23.9 \mathrm{~cm}$ on 3 July to $10.0 \mathrm{~cm}$ on 23 August.

Mean daily forages intake and refusals are reported in Table 1. During Period 1, refusals represented 13.3-21.3\% of the diet offered and were highly variable among the animals. During Period 2, refusals represented $5.3 \%, 4.3 \%$ and $16.2 \%$ of the alfalfa offered for L25, L50 and L75 lambs respectively. Mean dietary proportion of alfalfa was $27.7 \%, 52.2 \%$ and $74.8 \%$ for L25, L50 and L75 lambs during Period 1, and 25.8\%, 48.7\% and 62.4\% for L25, L50 and L75 lambs during Period 2 (Fig. 1).

The ADG during the experiment was affected by the treatment $(P<0.001)$; it was lower for L0 and L25 lambs than for L50 and L75 lambs $(P<0.001)$. Mean ADG was 136, 147, 191 and $224 \mathrm{~g} /$ day for L0, L25, L50 and L75 lambs respectively.

\section{2. $\delta^{15} N$ value of forages}

Average $\delta^{15} \mathrm{~N}$ value was 3.3\%o (ranging from $2.9 \%$ to $4.2 \%$ ) for cocksfoot and $0.7 \%$ (ranging from $-0.9 \%$ to $1.6 \%$ ) for alfalfa (Fig. 2).

\section{3. $\delta^{15} N$ value of longissimus thoracis muscle}

The $\delta^{15} \mathrm{~N}$ value of the LT muscle averaged 6.06\% (5.8-6.3\%o) for the L0 lambs, 5.77\%o (5.4-6.1\%o) for the L25 lambs, 5.43\%o (5.1$5.8 \%$ ) for the L50 lambs and 5.44\%o (5.2-5.7\%o) for the L75 lambs (Fig. 3). Coefficient of variation of the $\delta^{15} \mathrm{~N}$ value of the meat was $3.41 \%, 4.21 \%, 5.11 \%$ and $3.70 \%$ for groups L0, L25, L50 and L75 respectively. The $\delta^{15} \mathrm{~N}$ value of the meat was significantly affected by the experimental treatment $(P<0.001)$. It was higher for the L0 lambs than for the L25 lambs $(P<0.01)$ and higher for the L0 lambs than for the L50 and L75 lambs ( $P<0.001$ for both comparisons). The $\delta^{15} \mathrm{~N}$ value of the meat was higher for the L25 lambs than for the L50 and L75 lambs $(P<0.01)$. It was not different between the L50 and L75 lambs.

The $\delta^{15} \mathrm{~N}$ value of the meat was linearly related to the proportion of alfalfa $(P A, \%)$ in the diet $(P=0.024)$ (Fig. 4), with no significant quadratic effect $(P=0.599)$, the regression equation being:

$$
\begin{aligned}
\delta^{15} \mathrm{~N} \text { value of the meat }= & 6.04( \pm 0.071) \\
& -0.0107( \pm 0.00169) \mathrm{PA},
\end{aligned}
$$

where $r^{2}=0.95, \operatorname{RSD}=0.080$, and $n=4$.

\subsection{Discriminant analysis}

There was no overlap in the distribution of the $\delta^{15} \mathrm{~N}$ values of the LT muscle between the L0 and L75 lambs (Fig. 3). Discriminant analysis correctly classified $100 \%$ of the Lo lambs and $100 \%$ of the L75 lambs. There was some overlap in the distribution of the $\delta^{15} \mathrm{~N}$ values of the LT muscle between the L0 and L50 lambs (two

\section{Table 1}

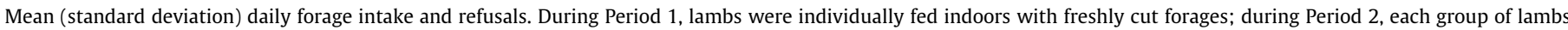

\begin{tabular}{|c|c|c|c|c|}
\hline Feeding treatment ${ }^{\mathrm{a}}$ & LO & L25 & L50 & L75 \\
\hline \multicolumn{5}{|l|}{ Period 1} \\
\hline Daily alfafa intake (kg DM $\left.{ }^{\mathrm{b}} / \mathrm{lamb}\right)$ & - & $0.184(0.0403)$ & $0.382(0.0357)$ & $0.563(0.0535)$ \\
\hline Daily cocksfoot intake (kg DM $\left.{ }^{\mathrm{b}} / \mathrm{lamb}\right)$ & $0.643(0.0682)$ & $0.482(0.0680)$ & $0.351(0.0408)$ & $0.189(0.0136)$ \\
\hline Refusals (proportion of the diet offered,\% $\mathrm{DM}^{\mathrm{b}}$ ) & $21.3(11.37)$ & $20.1(12.21)$ & $13.3(10.37)$ & $13.5(10.59)$ \\
\hline \multicolumn{5}{|l|}{ Period 2} \\
\hline Daily alfalfa intake (kg DM $/ \mathrm{lamb})$ & - & 0.269 & 0.545 & 0.716 \\
\hline Mean daily alfalfa refusals (kg DM $\left.{ }^{\mathrm{b}}\right)$ & - & 0.013 & 0.023 & 0.139 \\
\hline Refusals (proportion of the alfalfa offered, \% $\mathrm{DM}^{\mathrm{b}}$ ) & - & 3.7 & 3.7 & 15.7 \\
\hline
\end{tabular}
grazed a cocksfoot pasture and was supplemented with the assigned level of freshly cut alfalfa.

${ }^{a}$ Refer to the assigned dietary proportion of alfalfa (0\%, 25\%, 50\% and 75\% for L0, L25, L50 and L75 respectively).

b Dry matter. 
L0 lambs and two L50 lambs having a $\delta^{15} \mathrm{~N}$ value of the LT muscle of 5.8). The discriminant analysis correctly classified $100 \%$ of the L0 lambs and $77.8 \%$ of the $\mathrm{L} 50$ lambs (seven out of nine lambs), giving a global correct classification score of $88.2 \%$. The discriminant analysis between the L0 and L25 lambs correctly classified $75.0 \%$ of the L0 lambs (six out of eight lambs) and 77.8\% of the L25 lambs (seven out of nine lambs), giving a global correct classification score of 76.5\%. The discriminant analysis between lambs consuming no alfalfa (N, i.e. LO lambs) and those who consumed alfalfa (A, i.e. L25, L50 and L75 lambs) correctly classified $75.0 \%$ of the N lambs (six out of eight) and $88.5 \%$ of the A lambs (23 out of 26 ), giving a global correct classification score of $85.3 \%$. The linear discriminant analysis between the four experimental groups correctly classified $75 \%$ of the L0 lambs (six out of eight), $44.4 \%$ of the L25 lambs (four out of nine), $11.1 \%$ of the L50 lambs (one out of nine) and $0 \%$ of the L75 lambs, giving a global correct classification score of $32.4 \%$ for the samples.

\section{Discussion}

This work set out to study the dose-dependent response relating the proportion of legumes in the diet to the $\delta^{15} \mathrm{~N}$ value of lamb

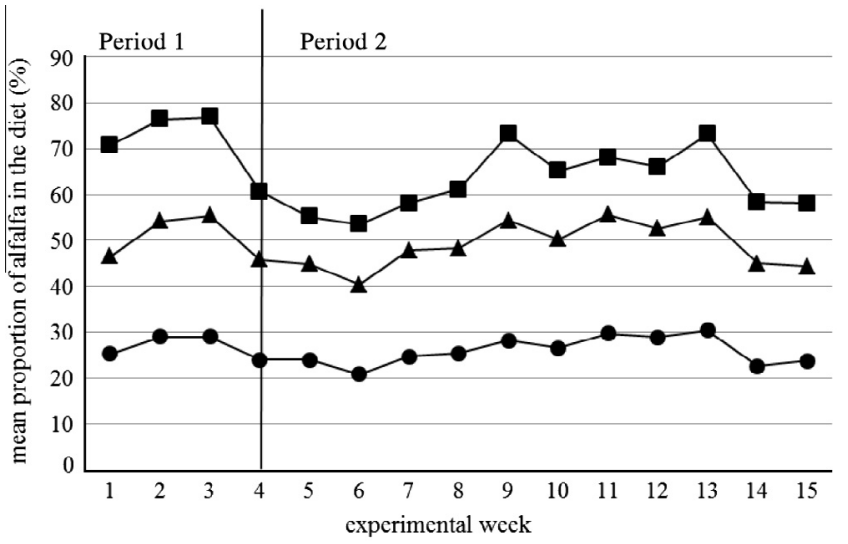

Fig. 1. Mean proportion of alfalfa in the diet of lambs according to the experimental week. Circles ( $\bullet$ ), triangles ( $\boldsymbol{\Lambda}$ ) and squares ( $\boldsymbol{\square}$ ) refer respectively to groups of lambs assigned to consume $25 \%, 50 \%$ and $75 \%$ of alfalfa in their diet. During Period 1 , the lambs were individually fed indoors with freshly cut cocksfoot and alfalfa. During Period 2, they were pasture-fed on a cocksfoot sward and supplemented with freshly cut alfalfa.

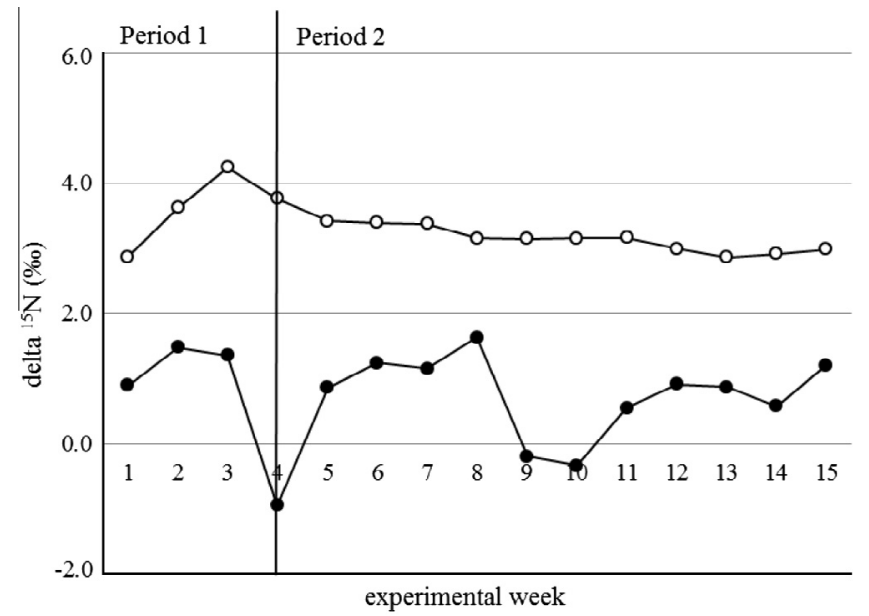

Fig. 2. Changes in $\delta^{15} \mathrm{~N}$ values of the forages according to the experimental week. White $(\bigcirc)$ and black $(\bullet)$ circles refer to the cocksfoot pasture and to alfalfa respectively. meat and to investigate the discriminatory ability of the $\delta^{15} \mathrm{~N}$ value of the meat for the authentication of meat produced from legumerich diets.

The experimental design was chosen both to ensure that the range of alfalfa proportions was sufficiently broad to obtain the response curve, and to limit the risk of bloating. The highest proportion of alfalfa also mimicked the preferences of ruminants on fields consisting of adjacent monocultures of grass and clover (Rutter, 2006).

It was initially planned to feed freshly cut forages to individually penned animals indoors (Period 1 ), in order to achieve an optimal individual control of cocksfoot and alfalfa intake levels. However, this experimental scenario was thwarted by low levels of forage intake, which resulted in low levels of ADG. Accordingly, we changed the experimental design during the second part of the study (Period 2) by (i) turning out each group of lambs to one cocksfoot plot and (ii) supplementing each group twice daily with freshly cut alfalfa. This change led to a marked improvement in ADG, but enabled the control of alfalfa intake only at group level.

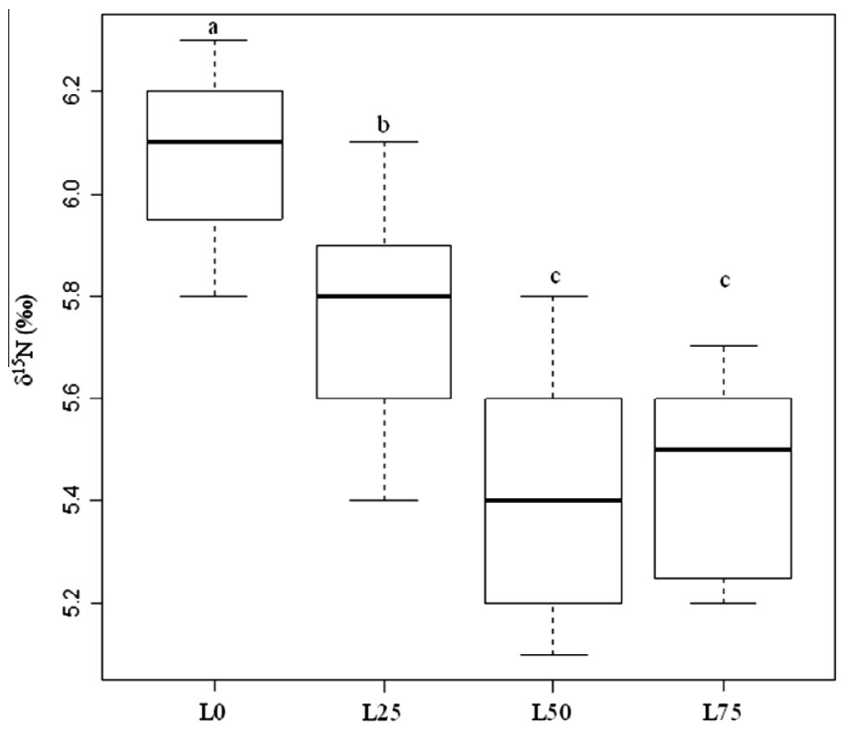

Fig. 3. Box plot representation of the $\delta^{15} \mathrm{~N}$ value of the longissimus thoracis muscle according to the level of fresh alfalfa supplementation in lambs grazing a cocksfoot pasture. The level of alfalfa supplementation was adjusted to achieve a proportion of alfalfa in the diet of 0\% (L0), 25\% (L25), 50\% (L50) and 75\% (L75). The box contains the middle $50 \%$ of the data, the upper edge of the box indicates the 75 th percentile of the data set, and the lower edge indicates the 25 th percentile. The bold line in the box indicates the median value of the data. The ends of the vertical lines indicate the minimum and maximum data values. Box plots not bearing a common letter are significantly different $(P<0.01)$.

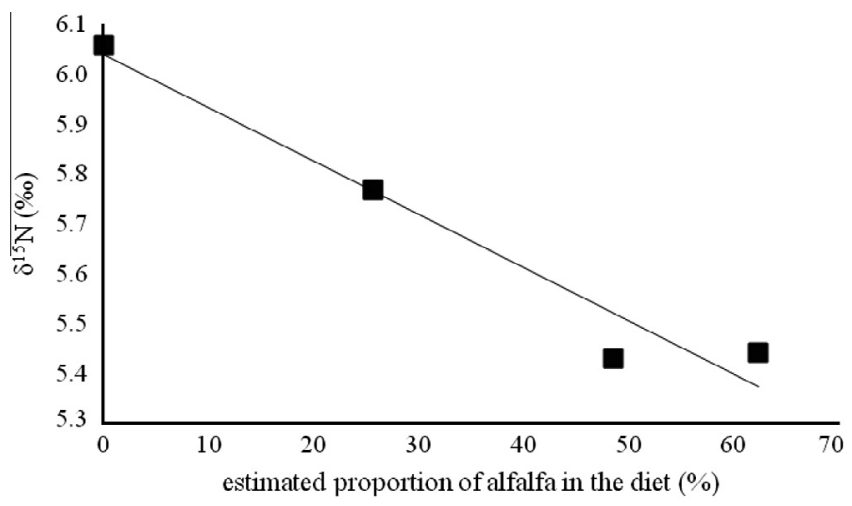

Fig. 4. Relationship between the mean proportion of alfalfa in the diet and $\delta^{15} \mathrm{~N}$ in lambs' longissimus thoracis muscle. 
During Period 1, the proportion of alfalfa in the diet was close to the assigned value for all the groups. During Period 2, the estimated proportion of alfalfa in the diet was close to the assigned value for L25 and L50 groups, but it was lower for L75 group (62.4\% vs. $75.0 \%$ ). However, the level of alfalfa refusals demonstrated that this forage was offered ad libitum to L75 lambs. The area and the management of the cocksfoot pasture were planned to ensure ad libitum intake (calculated as equal to $78.125 \mathrm{~g} \mathrm{DM} / \mathrm{BW}^{0.75}$ ), and consequently a satisfactory estimation of the proportion of alfalfa in the diet. The stocking rate was low (22.5 lambs/hectare) and the cocksfoot regrowth was in a vegetative stage throughout the experiment. However, we experienced drought conditions from mid-August onwards, which resulted in a lower mean sward surface height on the cocksfoot pasture than initially planned. The mean ADG for L25 lambs (147 g/d) indicated that voluntary intake may not always have been reached for this group. It follows that the proportion of alfalfa in the diet could have been somewhat over-estimated for L25 lambs. However, values for L50 and L75 lambs ADG (191 and $224 \mathrm{~g} / \mathrm{d}$ ) indicated that voluntary intake was reached for both groups, and so the proportion of alfalfa in the diet was satisfactorily estimated. Concerning the LO lambs, although their voluntary intake may not always have been reached, this was irrelevant to the estimation of the diet composition, as they ate only cocksfoot.

Cocksfoot and alfalfa $\delta^{15} \mathrm{~N}$ values lay in the range reported in previous studies (Rossmann, Kornexl, Versini, Pichlmayer, \& Lamprecht, 1998; Schwertl, Auerswald, Schaüfele, \& Schnyder, 2005). The ${ }^{15} \mathrm{~N}$ level of the nitrogen compounds in plants is lower for leguminous plants, because they utilize the nitrogen in the air, which is rich in ${ }^{14} \mathrm{~N}$, as a nitrogen source (Virginia \& Delwiche, 1982). The temporal changes in $\delta^{15} \mathrm{~N}$ observed during the course of the experiment were greater for alfalfa than for cocksfoot grass. The lower $\delta^{15} \mathrm{~N}$ values occasionally observed for alfalfa could be explained by the fact that we sporadically used an older field that was conterminal to the experimental field, as a result of a shortage of forage on the initially planned alfalfa pasture due to the onset of drought conditions. Owing to a more developed root system, older plants may have a greater ability to fix air nitrogen, increasing ${ }^{14} \mathrm{~N}$ in plant nitrogen compounds, and so decreasing the $\delta^{15} \mathrm{~N}$ value (Högberg, 1997).

The $\delta^{15} \mathrm{~N}$ values of the LT muscle were somewhat more variable between individual animals for the L25 and L50 lambs than for the L75 lambs, probably reflecting the inter-individual variability in animal preferences (Prache, Roguet, \& Petit, 1998; Prache, Bechet, \& Damasceno, 2006) and above all the higher competition for alfalfa. The inter-individual variability observed in this study is in line with that observed in beef meat (Bahar et al., 2005) and cattle hair (Schwertl et al., 2005).

There was a significant effect of the feeding treatment on the $\delta^{15} \mathrm{~N}$ value of the LT muscle, and one of the main results of the present study is that there was a negative linear relationship between the mean proportion of alfalfa in the diet and the mean $\delta^{15} \mathrm{~N}$ value of the lamb muscle. The declining value of muscle $\delta^{15} \mathrm{~N}$ clearly reflected the replacement of the cocksfoot pasture with alfalfa. In this regard, we note that as the between-animal variability in diet preferences may be high (Prache et al., 2006), the $\delta^{15} \mathrm{~N}$ value of the LT muscle may give relevant information to estimate the proportion of alfalfa in the diet for individual animals fed within groups.

A second main result of this study is that the $\delta^{15} \mathrm{~N}$ value of the LT muscle is a useful tool for discriminating lambs that consume legumes from those that do not. Although the discriminant analysis did not satisfactorily separate all the treatment groups, the distribution of the $\delta^{15} \mathrm{~N}$ values of the muscle for lambs that ate legumes (L25, L50 and L75 lambs) from those that did not (L0 lambs) gave a correct classification score of $85.3 \%$. Moreover, the distribution of the $\delta^{15} \mathrm{~N}$ values of the muscle for L0 and L75 lambs enabled us to discriminate the two groups fully. Hence $\mathrm{N}$ isotope composition in the meat can give relevant information to discriminate meat from lambs fed legume-rich diets, such as lambs produced in low-input and organic production systems. Actually, leguminous plants are more widespread in these production systems, which avoid or limit the use of synthetic fertilizers (Prache et al., 2011).

However, as $\delta^{15} \mathrm{~N}$ values of the LT muscle depend on $\delta^{15} \mathrm{~N}$ values in the diet, they may be modulated by the level and nature of the fertilization used on grasslands. In this regard, we note that organic fertilizers (for example, farmyard manure) increase the ${ }^{15} \mathrm{~N}$ in both soil and plants (Bateman, Kelly, \& Woolfe, 2007) and consequently in the meat of grazing animals (Yanagi et al., 2012).

Furthermore, compared with the present feeding scenario, in which the proportion of alfalfa in the diet remained steady throughout the fattening period, the proportion of legumes in a grazing animal's diet may vary greatly according to management practices of grasslands. There may be a high variability between pastures that are successively grazed in the contribution of legume species to the sward biomass (Bahar et al., 2008). There may also be a high variability between successive days during the grazingdown of a pasture, because animals may switch from the preferred legume species to the less preferred graminae species (Prache et al., 2006). These issues raise further questions such as the time of appearance and persistence of $\delta^{15} \mathrm{~N}$ values of the LT muscle relative to changes in diet.

Finally, it is likely that the $\mathrm{N}$ isotope signature of the meat cannot reveal intensive indoor fattening with concentrates containing legumes (such as soya bean, dehydrated alfalfa, or chickpea for example) (Bahar et al., 2005; Prache et al., 2009; Biondi et al., 2013). To yield a robust tool for the authentication of the meat produced from ruminants pasture-fed legume-rich pastures, the $\mathrm{N}$ isotope signature of the meat may therefore need to be combined with other methods, particularly those used for pasture-feeding authentication (Prache, 2007; Dian, Andueza, Jestin, Prado, \& Prache, 2008).

\section{Conclusion}

This study demonstrates that the $\delta^{15} \mathrm{~N}$ value of the longissimus thoracis muscle decreases linearly with the proportion of legume in the diet and can give relevant information to authenticate meat from lambs fed legume-rich diets.

These results may be of interest for the authentication of meat produced in low-input and organic production systems, in which leguminous plants are more widespread. In this regard, further work should be directed at combining $\delta^{15} \mathrm{~N}$ value of the meat with other methods to increase the reliability of the discrimination and avoid the risk of bias.

\section{Acknowledgements}

We thank F. Anglard, P. Payard, L. Lavelle, C. Coustet, S. Faure and all staff of the INRA Theix Experimental Unit for their collaboration. We gratefully acknowledge funding from the European Community financial participation under the Seventh Framework Program for Research, Technological Development and Demonstration Activities, for the Integrated Project LOWINPUTBREEDS FP7-CP-IP 222623. The views expressed in this publication are the sole responsibility of the authors and do not necessarily reflect the views of the European Commission. T. Devincenzi thanks the Brazilian Ministry of Education "Coordenação de Aperfeiçoamento de Pessoal de Nivel Superior (Capes) for providing financial assistance via Capes/PSDE №. BEX 9718/11-7 and the "Conselho Nacional de Desenvolvimento Cientifico e Tecnologico" (CNPq) for a scholarship. 


\section{References}

Bahar, B., Monahan, F. K., Molony, A. P., O’Kiely, P., Scrimgeour, C. M., \& Schmidt, O. (2005). Alteration of the carbon and nitrogen stable isotope composition of beef by substitution of grass silage with maize silage. Rapid Communications in Mass Spectrometry, 19, 1937-1942.

Bahar, B., Schmidt, O., Moloney, A. P., Scrimgeour, C. M., Begley, I. S., \& Monahan, F. J. (2008). Seasonal variation in the C, N and S stable isotope composition of retail organic and conventional Irish beef. Food Chemistry, 106, 1299-1305.

Bateman, A. S., Kelly, S. D., \& Woolfe, M. (2007). Nitrogen isotope composition of organically and conventionally grown crops. Journal of Agricultural and Food Chemistry, 55, 2664-2670.

Biondi, L., D’Urso, M. G., Vasta, V., Luciano, G., Scerra, M., Priolo, A., et al. (2013). Stable isotope ratios of blood components and muscle to trace dietary changes in lambs. Animal, 7(9), 1559-1566.

Camin, F., Bontempo, L., Heinrich, K., Horacek, M., Kelly, S. D., Schlicht, C., et al. (2007). Multi-element (H, C, N, S) stable isotope characteristics of lamb meat from different European regions. Analytical and Bioanalytical Chemistry, 389, 309-320.

DeNiro, M., \& Epstein, S. (1981). Influence of diet on the distribution of nitrogen isotopes in animals. Geochimica et Cosmochimica Acta, 45, 341-351.

Dian, P. H. M., Andueza, D., Jestin, M., Prado, I. N., \& Prache, S. (2008). Comparison of visible and near infrared reflectance spectroscopy to discriminate between pasture-fed and concentrate-fed lamb carcasses. Meat Science, 80, 1157-1164.

Hassoun, P., \& Bocquier, F. (2007). Alimentation des ovins. In INRA (Ed.), Alimentation des bovins, ovins et caprins - Besoins des animaux - Valeurs des aliments (pp. 121-136). Versailles: Editions Quæ.

Högberg, P. (1997). Tansley Review No. 95. ${ }^{15} \mathrm{~N}$ natural abundance in soil-plant systems. New Phytologist, 137, 179-203.

INRA (2007). Tableaux de la valeur des aliments. In Alimentation des bovins, ovins et caprins - Besoins des animaux - Valeurs des aliments (pp. 184-217). Editions Quæ: Versailles.

Monahan, F. J., Moloney, A. P., Osorio, M. T., Röhrle, F. T., Schmidt, O., \& Brennan, L. (2012). Authentication of grass-fed beef using bovine muscle, hair or urine. Trends in Food Science E Technology, 28, 69-76.

Piasentier, E., Valusso, R., Camin, F., \& Versini, G. (2003). Stable isotope ratio analysis for authentication of lamb meat. Meat Science, 64, 239-247.

Prache, S. (2007). Developing a diet authentication system from the composition of milk and meat in sheep: A review. Journal of Agricultural Science, 145, 435-444.
Prache, S., Roguet, C., \& Petit, M. (1998). How degree of selectivity modifies foraging behaviour of dry ewes on reproductive compared to vegetative sward structure. Applied Behaviour Science, 57, 91-108.

Prache, S., \& Peyraud, J. L. (2001). Foraging behaviour and intake in temperate cultivated grasslands. In José Alberto Gomide, Wilson Roberto Soares Mattos, \& Sila Carneiro da Silva (Eds.), Proceedings of the XIX international grassland congress (pp. 309-319). Piracicaba: FEALQ.

Prache, S., Bechet, G., \& Damasceno, J. C. (2006). Diet choice in grazing sheep: A new approach to investigate the relationships between preferences and intake-rate on a daily time scale. Applied Animal Behaviour Science, 99, 253-270.

Prache, S., Kondjoyan, N., Delfosse, O., Chauveau-Durio, B., Andueza, D., \& Cornu, A. (2009). Discrimination of pasture-fed lambs from lambs fed dehydrated alfalfa indoors using different compounds measured in the fat, meat and plasma. Animal, 3(4), 598-605.

Prache, S., Gatellier, P., Thomas, A., Picard Bauchart, D., B., \& Bauchart, D. (2011). Comparison of meat and carcass quality in organically reared and conventionally reared pasture-fed lambs. Animal, 5(12), 2001-2009.

Rossmann, A., Kornexl, B. E., Versini, G., Pichlmayer, F., \& Lamprecht, G. (1998). Origin assignment of milk from alpine regions by multielement stable isotope ratio analysis (Sira). Journal of Food Science \& Nutrition, 1, 9-21.

Rutter, S. M. (2006). Diet preference for grass and legumes in free ranging domestic sheep and cattle: Current theory and future application. Applied Animal Behaviour Science, 97, 17-35.

Schmidt, O., Quilter, J. M., Bahar, B., Moloney, A. P., Scrimgeour, C. M., Begley, I. S., et al. (2005). Inferring the origin and dietary history of beef from C, N and S stable isotope ratio analysis. Food Chemistry, 91, 545-549.

Schwertl, M., Auerswald, K., Schaüfele, R., \& Schnyder, H. (2005). Carbon and nitrogen stable isotope composition of cattle hair: Ecological fingerprints of production systems? Agriculture, Ecosystems and Environment, 109, 153-165.

Vinci, G., Preti, R., Tieri, A., \& Vieri, S. (2012). Authenticity and quality of animal origin food investigated by stable-isotope ratio analysis. Journal of Science of Food and Agriculture, 93(3), 439-448.

Virginia, R. A., \& Delwiche, C. C. (1982). Natural N-15 abundance of presumed $\mathrm{N}_{2}$ fixing and non- $\mathrm{N}_{2}$-fixing plants from selected ecosystems. Oecologia, 54, 317-325.

Yanagi, Y., Hirooka, H., Oishi, K., Choumei, Y., Hata, H., Arai, M., et al. (2012). Stable carbon and nitrogen isotope analysis: A tool for inferring beef cattle feeding systems in Japan. Food Chemistry, 134, 502-506. 